\title{
Collaboration between Villanova University and UNICEF's Innovation Lab at BICU, Nicaragua
}

\author{
Pritpal Singh, $\mathrm{PhD}^{1}$, \\ ${ }^{1}$ Villanova University, USA, Pritpal.singh@villanova.edu
}

\begin{abstract}
The United Nations Children's Fund (UNICEF) has established innovation labs throughout the world to develop innovative solutions to problems related to children and youth. The UNICEF Innovation lab in Nicaragua was located at the Bluefields Indian and Caribbean University (BICU) in Bluefields, Nicaragua. Faculty and students from Villanova University and Colleges and Universities in Managua, Nicaragua have worked with students and professors at BICU to deliver workshops in product design, solutions development, and entrepreneurship to BICU students. This paper presents a description of these activities and the informal assessment of this work to date.
\end{abstract}

Keywords-Outreach, globalization, entrepreneurship.

\section{INTRODUCTION}

The United Nations Children's Fund (UNICEF) is the world's pre-eminent organization that works on improving the condition of children and youth around the world [1]. In 2009, UNICEF established an Innovation program to stimulate the development of innovative solutions to challenges faced by children and youth in developing countries [2]. In support of this program, some UNICEF country offices established Innovation labs to work with children and youth to develop local innovations to address local problems.

Nicaragua is the second poorest country in the Western Hemisphere. Over half of the Nicaraguan population resides in the southwest, Pacific side of the country around the capital city of Managua. The Atlantic/Caribbean coastal region of Nicaragua is much less developed than the Pacific coastal region of the country. The Atlantic/Caribbean region is divided into two autonomous regions - the North Atlantic Autonomous Region (RAAN) and the South Atlantic/Caribbean region (RAAS) (see Fig. 1). These areas are very sparsely populated and lack significant infrastructure, especially roads. To travel from Managua to Bluefields over land, the normal route involves driving to Rama and then taking a two hour boat ride to Bluefields. While there is an airport at Bluefields, the cost of the air flight is quite prohibitive for local residents in the RAAN and RAAS regions.

There is a lot of poverty in these two regions due to the lack of both physical infrastructure as well as economic activity. Unlike the Pacific side of the country, these regions contain several ethnic groups including indigenous people, people of Afro-Caribbean descent, as well as Mesquite and Mestito ethnic groups [3]. There is a lot of youth unemployment, violence, teenage pregnancy, and other problems in this region. The UNICEF country office in Nicaragua therefore located the Innovation laboratory in Bluefields, Nicaragua to develop solutions to address some of these problems.

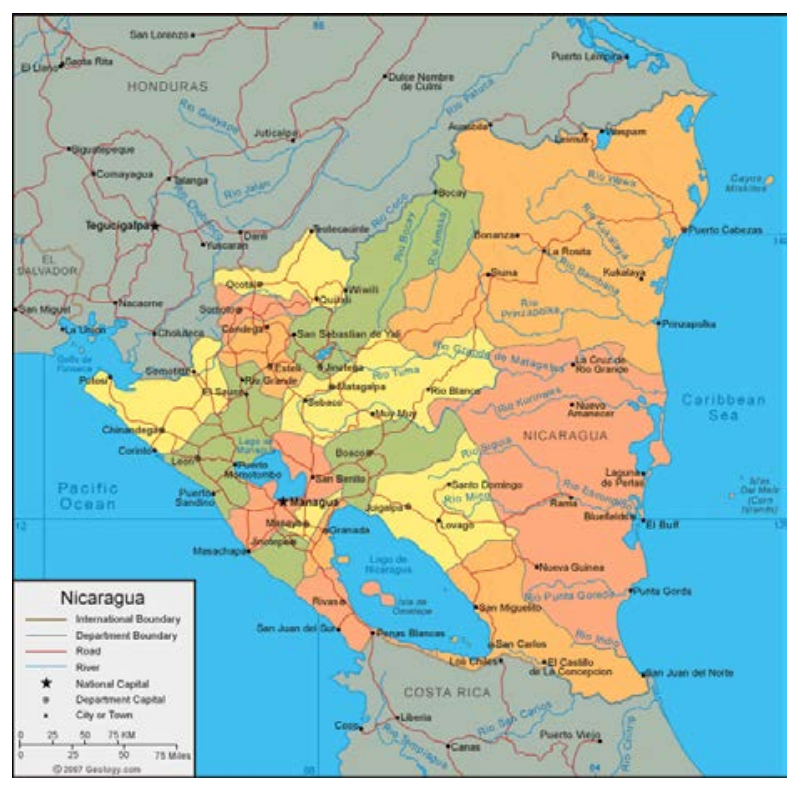

Figure 1. Map of Nicaragua

\section{UNICEF INNOVATION LABORATORY INITIATIVES}

UNICEF has conducted a number of design thinking workshops, human-centered design activities, design camps, and solutions prototyping activities through this innovation lab over the last four years. These activities have been performed in collaboration with the autonomous regional government of the South Atlantic and Caribbean (RAAS) region of Nicaragua.

An initial initiative comprised asking children in different communities to take photographs of different areas where they felt happy and where they felt sad. These pictures were then posted on the wall of an office in the regional government offices of the RAAS government. A photograph of this picture wall is shown in Figure 2. The children were also asked to sketch themselves and write about themselves and these posters were also affixed to a wall in the same RAAS government office, which served as the initial UNICEF innovation lab. Following these activities, the children were 
asked to focus on a single issue - improving the quality of the environment in their communities. Brainstorming sessions were then held to consider how to clean up the rivers (many of these children live in island communities along rivers), clean up trash, reduce animal waste, etc. The children then worked with UNICEF staff to develop potential solutions. Some of these solutions were implemented in the communities.

A second innovation camp was conducted by UNICEF in summer 2015. Children interviewed members of their communities under the guidance of UNICEF staff. Two problem areas emerged from these interviews - teenage pregnancy and drug and alcohol abuse. The students had to then come up with sustainable, entrepreneurial solutions to address these challenges.

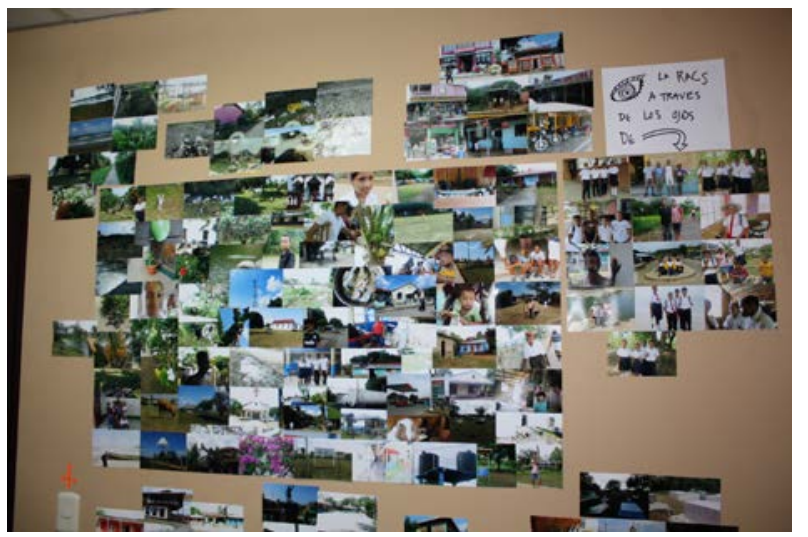

Figure 2. Picture Wall of Photographs taken by Children in the RAAS region of Nicaragua.

In May 2014, Dr. Pritpal Singh met Mr. Chris Fabian, CoLead of UNICEF's Innovation Program at a conference and was introduced to Ms. Rinko Kinoshita, Deputy Country Representative of UNICEF Nicaragua at the time. She expressed a strong interest in working with the faculty and students at Villanova University and in October 2014, a Cooperation Agreement was signed by Villanova University and UNICEF's country office in Nicaragua to collaborate on initiatives particularly in the areas of mHealth, entrepreneurship, social innovation and real-time monitoring. Prof. Singh saw this as an opportunity to have Villanova students work on service learning projects to benefit the children and youth of the RAAS region of Nicaragua. The initial meetings between Prof. Singh, his students, regional government officials of the RAAS region and UNICEF officials took place in October 2014 in Bluefields, Nicaragua. Earlier in 2014, the UNICEF Innovation Lab was moved from the regional government offices to an office space in the Bluefields and Indian Caribbean University (BICU) in Bluefields. The mission of the university is to educate the indigenous populations of the Caribbean coastal region of
Nicaragua and seemed like a better place to locate the Innovation Lab than in the regional government offices. Also, the goal for UNICEF was to transfer ownership of the lab to BICU in a short time. Since his first visit to the Innovation Lab in October 2014, Prof. Singh and his students have traveled several times to Bluefields and other areas in the RAAS region to deliver workshops, perform projects and conduct activities with the local communities and students.

The remainder of this paper describes the workshops and activities performed by Villanova professors and students in collaboration with UNICEF and the BICU Innovation Lab.

\section{VILLANOVA WORKSHOPS AND ACTIVITIES}

\section{A. Social Innovation and Entrepreneurship Workshops}

Several workshops have been conducted at BICU by Villanova faculty and students starting in May 2015. The initial workshop was focused on brainstorming, basic concepts of entrepreneurship, and simple business model development. Students from BICU, guided by social design thinking experts from UNICEF, conducted an innovation camp in the summer of 2015 in which the participants were asked to identify some local problems in their communities and to develop concepts for addressing these problems. One of the problems that was considered was reducing the incidence of teenage pregnancy. BICU students (as well as students from another local university, URRACAN, and youth from the region) conducted the needs assessment and then developed and prototyped solutions. In a fall break trip in October 2015, a workshop on developing the solutions using sustainable business models was conducted by Villanova personnel as well as two students from American College in Managua. The two students from Managua were members of the Entrepreneurship Club at American College and had previously worked with UNICEF's Nicaragua country office in other initiatives in a poor community on the Pacific coast of Nicaragua. A photograph of BICU students engaged in an Innovation Workshop at UNICEF is shown in Fig. 3. The BICU and HURRACAN students worked on brainstorming solutions and developing prototypes. These solutions and prototypes were critiqued and improved. The youth were then supposed to implement these solutions in their communities. However, the follow up by the local students after the workshop was disappointingly limited.

In May 2016, a workshop was again conducted on the topic of entrepreneurship to a different group of students from both BICU and HURRACAN. In this case, several exercises revolving around starting and building a business were conducted. One of the exercises conducted in this workshop was developed by Prof. Tina Seelig of Stanford University that Prof. Singh has used before in entrepreneurship classes that he has taught at Villanova University. In this exercise, students are asked to develop a plan to increase a seed investment that

$16^{\text {th }}$ LACCEI International Multi-Conference for Engineering, Education, and Technology: "Innovation in Education and Inclusion”, 19-21 July 2018, Lima, Peru. 
they will be given in a sealed envelope. They are told that they will have only two hours to increase their investment. The agreement made with the students was that whatever additional money the students made beyond the initial seed investment was theirs to keep while the initial seed investment had to be returned to the instructor.

When students opened the envelopes, they were generally surprised and disappointed to see how little money was given to them. The amount was only 10 cordobas, less than US 50 cents! Nevertheless, the students came up with different ways of increasing the money, e.g. conducting raffles, providing services for other students, etc. In the end all of the students made several dollars and were very pleasantly

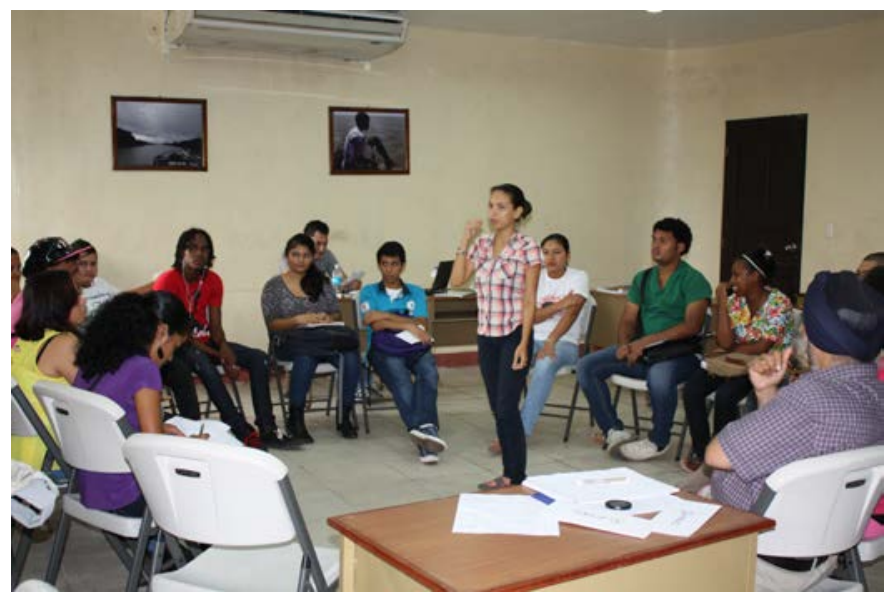

Figure 3. Photograph of students engaged in an activity at an Entrepreneurship Workshop at BICU

surprised at their accomplishments. This exercise is designed to help students realize that they are able to make money fairly easily. This exercise was very eye-opening to the BICU students.

The students came up with several ideas for starting business ventures including establishing a photography business, selling blended juices, opening a dance studio and offering self-defense classes. It was encouraging to see the students come up with some very good, feasible ideas for businesses.

During this visit, a seminar was presented on networking and partnerships. An exercise that was conducted during this session was to have the members of the audience turn to a partner and explore whether they had a common acquaintance in Managua. This was followed by a similar exercise but this time the partners had to find a common friend/relative who lives in the United States. This exercise proved to be very insightful. Only one pair of students had a common friend in Managua and nobody had a common friend/relative in the
United States. The number of attendees at this session was over 100! The results of this exercise underscored how isolated are the members of the communities in this region of the country.

\section{B. Technology Workshops and Seminars}

In addition to entrepreneurship and social innovation workshops, more recently Prof. Singh and his students have delivered technical workshops to students at BICU. In May 2016, Prof. Singh presented an Arduino workshop using the Sparkfun Inventors kit [5]. The Arduino microcontroller is a low cost microcomputer that may be interfaced to devices such as lights, motors, buzzers, etc. By programming the microcontroller, the student can cause lights to turn on and off, motors to turn, buzzers to sound, etc. The purpose of the workshop was to show students how the Arduino microcontroller could be programmed to perform these functions. The Sparkfun Inventors kit is a self-contained kit that includes the Arduino microcontroller, a breadboard for building circuits, wires to connect the devices and a range of electronic components and devices to which the microcontroller may be interfaced.

Unfortunately, of the 5 kits taken down to Nicaragua, only two of the microcontroller boards worked. So the class of 25 students had to share these two boards. Nevertheless, the students really enjoyed seeing what can be done with basic Arduino microcontrollers. The one-day workshop proved to be too short and the BICU students asked for us to provide a more extensive workshop. Two Villanova electrical engineering students who were doing internships at a local company, Blue Energy (based in Bluefields and headquartered close to BICU) gave an extended workshop to the BICU students later on that summer. It was very well received by the BICU students. Five of the kits were available for the students and so they were able to work in smaller groups with the kits than when Prof. Singh delivered his workshop.

A workshop on developing applications for Androidbased mobile phones and tablets was presented by Villanova students in May 2017. The BICU students were taught how to use the Android Studio application development software to develop mobile applications. This two day workshop was very well received by the BICU students and the Villanova students also really enjoyed the experience. While BICU does offer engineering and computer science classes, the level of these classes is relatively low, even compared to classes taught at public universities in Managua.

On this trip, Prof. Singh also gave a workshop on fiber optic communications since a new fiber optic line is being installed in the Atlantic coastal region and the students at BICU requested a seminar on this topic. 


\section{C. mHealth Project}

Another area of interest of UNICEF is that of mobile health (mHealth). Since many of the communities in the RAAN and RAAS regions are very dispersed, community members often have a difficult time to access quality health care in these regions of the country.

A mHealth project has been developed by Villanova professors and students and has been operating in the North Central region of Nicaragua since 2010 [6]. This project provides access to improved health care in rural communities in the RAAN region. The concept of the project is to first train community health workers to measure basic vital signs, such as blood pressure, temperature, pulse rate, etc. This information is then texted using basic feature phones to a computer server where the data is stored in an electronic medical record developed using open source UNICEF software called RapidSMS. A health care professional then reviews the medical record and advises community health workers to have individuals whose vital signs are out of a normal range to be referred for further checkup at a local hospital. Nursing, engineering and business professors and students jointly developed and implemented the project.

UNICEF and the regional government in the RAAS region were interested in conducting a pilot project similar to this on the island of Laguna de Perlas. Students and professors from Villanova worked with a student intern (a graduate from BICU) to develop and implement this system using a newer, cloud-based, UNICEF software called RapidPro. A comparison of the RapidPro and Rapid SMS tools were presented in [6]. Figure 4 shows a photograph of a group of community health workers discussing the project with representatives from the regional government, Villanova University and UNICEF. This project has been running for about one year now.

\section{IMPACT OF COLLABORATION}

The Villanova collaboration with the UNICEF Innovation lab at BICU has been very positive. As mentioned earlier, BICU is a relatively isolated university and so interactions with outsiders have been limited. It is also a very resource constrained university and so providing the students with resources for electronic prototyping, such as the Sparkfun Inventors kits has given the students an opportunity to further develop their technical skills in the area of electronic hardware design and construction. The entrepreneurship workshops have helped to increase the self-efficacy of the students. The mobile applications classes have been very well received by the BICU students and the technology seminars have exposed the students at both BICU and HURRACAN information about new technologies. All of the informal feedback/assessment from BICU and HURRACAN students and faculty has been very positive. The students from Villanova have also found the experience of working with the BICU students very rewarding. They are so excited to share their knowledge and enjoy seeing the BICU students absorb the material that they are teaching so well.

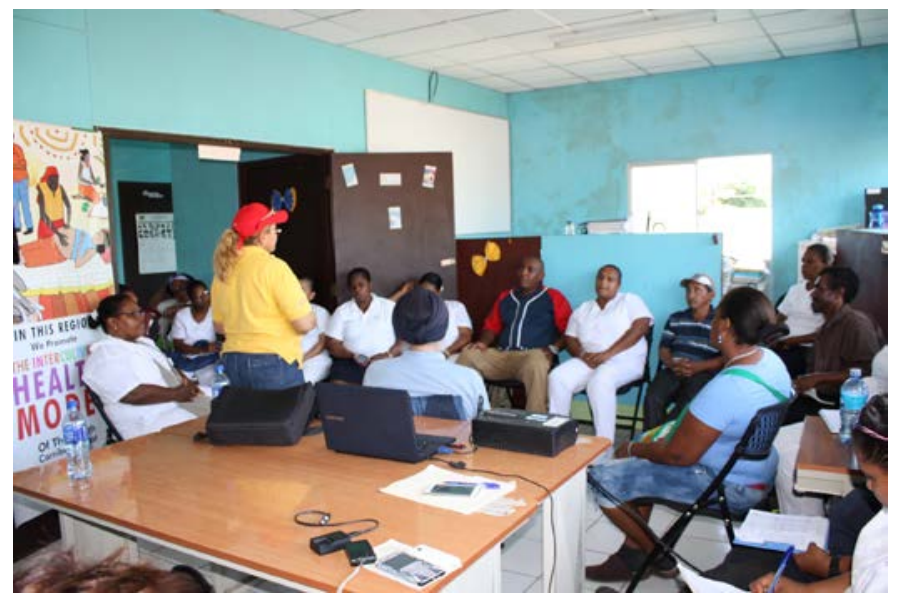

Figure 4. Meeting with Community Health Workers in Laguna de Perlas

\section{STATUS OF THE BICU INNOVATION LAB}

UNICEF's goal in its innovation programs is to initiate the opportunity and then develop the programs in collaboration with local partners until they can be self-sustaining. At that point, UNICEF transfers ownership of the Innovation lab to a local entity. This has happened with the BICU Innovation lab. While the lab was launched by UNICEF in collaboration with BICU, it has now been fully adopted by BICU. The administrators and staff at BICU have been successful in raising funds to support the lab's activities. They hired a Lab Coordinator, Ariana Arguello, who is a BICU graduate and participated in the first workshop that Prof. Singh conducted at BICU.

Through the Innovation Lab, BICU started a Robotics Club. The students from the Robotics Club have previously participated in the technical workshops offered by Prof. Singh and his students at BICU. The students designed and built their own robot and then participated in a regional robotics competition which they handily won! They went on to compete in a national competition where the team earned a first place finish [7]! It is the author's belief that the technical workshops delivered by Villanova students and Prof. Singh had a hand in exciting and motivating BICU students to both establish the Robotics Club and then to work hard in designing, building and testing their robots so that they become winners of the regional and national competitions. 


\section{CONCLUSIONS}

Villanova University professors and students have collaborated with UNICEF to deliver workshops on technology and entrepreneurship to children and youth located in the impoverished RAAS region of Nicaragua. These workshops have been conducted for the last three years and have been performed through an Innovation lab established by UNICEF at BICU. While the original goal of using the UNICEF Innovation lab to co-create solutions to local problems in the RAAN and the RAAS regions of Nicaragua has not yet been met, the lab has come a long way over the past four years. The engagement of Villanova students and faculty has benefited the lab significantly as well as providing rewarding experiences for the Villanova students and faculty. Prof. Singh plans to continue to bring Villanova students down to Bluefields to collaborate with BICU students and the Innovation lab to co-develop solutions to local challenges. However, because of the recent political unrest in the country, a trip planned for June 2018 was postponed until the political situation in the country stabilizes.

\section{ACKNOWLEDGMENT}

The author is grateful to former and present UNICEF personnel including Rinko Kinoshita, Milja Laakso, Natalia Adler, Dr. Rafael Amador, Kevin Mendes, Emmanuel Michaud, and Gerardo Escaroz. He is also grateful to Villanova students Sajid Hossain, Chris Dixon, Maddie Lopez and Ethan Fortin for their help with workshops and mHealth work in Bluefields and El Bluff. He is also grateful to Venture Well for funding entrepreneurship activity in Nicaragua. Finally, the author is grateful to all the students and faculty at BICU and particularly Ariana Arguello and Prof. Kevin Lopez for hosting him at BICU.

\section{REFERENCES}

[1] www.unicef.org [Accessed March 15, 2018]

[2] https://www.unicef.org/innovation/ [Accessed March 15, 2018]

[3] http://www.nicaragua-guide.com/the-people.html [Accessed March 15, 2018]

[4] P. Singh, R. McDermott-Levy, E. Keech, B. Mariani, J. Klingler and M.V. Moncada, "Challenges and Successes in Making Health Care More Accessible to Rural Communities in Waslala, Nicaragua Using Low-Cost Telecommunications", Procs. 2013 IEEE Global Humanitarian Technology Conf., Oct. 20-22, 2013 (San Jose, CA)

[5] https://www.sparkfun.com/sparkfun_inventors_kit [Accessed March 15, 2018]

[6] P. Singh, "Employing UNICEF Open Source Software Tools in mHealth Projects in Nicaragua", Procs. Ubiquitious Computing and Ambient Intelligence (UCAmI) 2016 conference, Nov. 29-Dec. 2, 2016 (Las Palmas, Gran Canaria, Spain)

[7] https://www.youtube.com/watch?v=pUKhmqrSj6s [Accessed March 15, 2018]

$16^{\text {th }}$ LACCEI International Multi-Conference for Engineering, Education, and Technology: "Innovation in Education and Inclusion”, 19-21 July 2018, Lima, Peru. 